\title{
PENGATURAN PENGgUNAAN SURAT ORDER DALAM PROSES PENGIKATAN AGUNAN KREDIT BERUPA HAK TANGGUNGAN
}

\author{
Oleh: \\ I Made Bagus Dwiki Praja Utama \\ I Ketut Rai Setiabudhi \\ Ida Bagus Wyasa Putra \\ Program Magister Kenotariatan Universitas Udayana \\ Email: dwiki.praja@yahoo.com
}

\begin{abstract}
ABSTRAK
Proses pemberian kredit sampai pendaftaran Hak Tanggungan diawali dengan pembuatan Surat Order oleh bank yang diberikan kepada Notaris. Surat order dibuat untuk mengakomodir proses pemberian kredit ketika Notaris tidak bertemu langsung dengan bank, agar Notaris memiliki suatu pegangan dan kepercayaan dari bank atas pertanggungjawaban dari agunan sehingga dapat dikeluarkan covenote dan APHT. Terdapat kekosongan norma dalam pengaturan penggunaan surat order sebagaimana diatur dalam Pasal 10 ayat (1) Undang-Undang Nomor 4 Tahun 1996 tentang Hak Tanggungan atas Tanah Beserta Benda-Benda yang Berkaitan dengan Tanah. Permasalahan yang dibahas dalam penulisan tesis ini difokuskan mengenai pengaturan surat order dalam peraturan perundang-undangan yang mengatur pengikatan agunan kredit perbankan dan formulasi pengaturan surat order untuk menjamin kepastian dan validitas Covernote dan Akta Pemberian Hak Tanggungan.

Jenis metode penelitian yang digunakan untuk menjawab permasalahan adalah metode penelitian hukum normatif, dengan menggunakan jenis pendekatan yaitu pendekatan perundang-undangan dan pendekatan historis. Bahan hukum primer adalah diperoleh dari peraturan perundang-undangan dan penetapan pengadilan. Bahan hukum sekuder diperoleh melalui berbagai literatur dan media lainnya yang sesuai dengan syarat penulisan tesis.

Hasil penelitian menunjukkan bahwa pengaturan penggunaan Surat Order dalam Peraturan Perundang-undangan yang mengatur pengikatan agunan kredit perbankan masih tidak memadai untuk digunakan. Terdapat kekosongan norma pada Pasal 10 UUHT mengenai pengaturan terhadap persyaratan dan penggunaan Surat Order dalam menjamin validitas data-data sebelum dikeluarkannya covernote dan APHT oleh notaris/PPAT. Selanjutnya, Formulasi pengaturan Surat Order untuk menjamin validitas dan memberikan kepastian hukum dari Covernote dan APHT dilakukan dengan membuatkan aturan yang tertuang pada Peraturan OJK sebagaimana telah sesuai dengan kewenangannya berdasarkan undang-undang untuk memberikan pengaturan terhadap bank. Pembuatan aturan baru oleh OJK adalah untuk mengisi kekosongan norma pada pengaturan persyaratan dan penggunaan Surat Order dalam proses pengikatan agunan kredit; dan untuk menjamin valid atau tidak validnya datadata yang dituangkan di dalam covernote dan APHT. Pembuatan aturan dilakukan dengan menambahkan pengaturan mengenai persyaratan Surat Order, bentuk resmi Surat Order, dan penggunaan Surat Order dalam proses pengikatan agunan kredit.
\end{abstract}

\section{Kata Kunci: Perbankan, Kredit, dan Surat Order}

\section{ABSTRACT}

The Bank loan process until its registration begins with the making of Mortgage Order Letter by banks which given to the Notary. Mortgage Order Letter is made to accommodate the credit approval process when the Notary not meet directly with the bank, so that the Notary has a grip and trust of the banks on the accountability of the collateral then notary/PPAT can send the cover note and APHT to the bank. The void of norms has found in the norms on regulating the use of Mortgage Order Letter as stated in Article 10 paragraph (1) of Indonesian Law number 4 year 1996 on Mortgage of Land and Their Bodies Related to Land (UUHT). The problems discussed in this thesis are focused on the regulation on Mortgage Order Letter in 
national law and the law formulation to ensure the certainty and validity of cover note and Granting Mortgage Deed.

Types of research methods used to answer the problem is a normative legal research methods by using statute and historical approach. Primary legal materials are derived from legislation and court determination. Secondary legal materials obtained through a variety of literature and other media in accordance with the terms of writing a thesis.

The results showed that the use of Mortgage Order Letter in the legislation that regulates the binding of collateral objects are still not adequate for use. There is void of norms in Article 10 UUHT which concerning the regulation of terms and the use of Mortgage Order Letter in ensuring the validity of the collateral data prior to the issuance on cover note and Granting Mortgage Deed by notary. Furthermore, The Letter of Order's law formulation is to ensure validity and provide legal certainty from Covernote and APHT shall be made by making the rules contained in the BI and OJK Regulations as already in accordance with their authority under the law in order, to provide the regulation of the bank. The enactment of new rules by BI and OJK is to fill the void of norms on the regulation of the requirements and the use of Order Letter in the process of binding of collateral for credit; And to ensure valid or invalidation of data poured in the covernote and APHT. The law making is done by adding the arrangement of Letter of Order requirement, Formal Letter of Order form, and the usage of Letter of Order in the process of binding of credit collateral.

Keywords: Banks, Loan, and Mortgage Order Letter.

\section{PENDAHULUAN}

\subsection{Latar Belakang}

Prinsip kehati-hatian bank, sebagaimana diatur dalam Pasal 2 Undang-Undang Republik Indonesia nomor 10 Tahun 1998 tentang Perubahan Atas UndangUndang Nomor 7 Tahun 1992 tentang Perbankan (UU Perbankan) menentukan bahwa dalam memberikan kredit kepada nasabahnya diperlukan Collateral (jaminan yang dimiliki calon debitur). Jaminan adalah segala sesuatu yang diterima kreditur dan diserahkan debitur untuk menjamin suatu utang piutang dalam masyarakat. Berdasarkan ketentuan Pasal 2 ayat (1) Surat Keputusan Direksi Bank Indonesia Nomor 23/69/KEP/DIR tanggal 28 Februari 1991 tentang Jaminan Pemberian Kredit, yang dimaksud dengan jaminan adalah suatu keyakinan bank atas kesanggupan debitur untuk melunasi kredit sesuai dengan yang diperjanjikan. ${ }^{1}$ Fungsi utama dari jaminan adalah untuk meyakinkan bank atau

${ }^{1}$ Hermansyah, 2008, Hukum Perbankan Nasional Indonesia, Kencana Prenada Media, Jakarta, h. 43. kreditur bahwa debitur mempunyai kemampuan untuk melunasi kredit yang diberikan kepadanya sesuai dengan perjanjian kredit yang telah disepakati bersama.

Proses penerbitan kredit sampai pendaftaran Hak Tanggungan diawali dengan pembuatan Surat Order oleh bank yang diberikan kepada Notaris. Pembuatan Surat Order itu dilanjutkan dengan pembuatan Perjanjian Kredit dalam bentuk akta dibawah tangan/ Notariil. Proses tersebut dilanjutkan dengan pembuatan Akta Pemberian Hak Tanggungan (APHT). APHT yang dibuat wajib didaftarkan di Kantor Pertanahan. Surat order adalah surat yang diterbitkan oleh bank untuk Notaris, yang memuat hal meminta bantuan jasa Notaris dalam proses pendaftaran Hak Tanggungan terhadap agunan yang diberikan oleh debitur kepada kreditur. Tujuan dari dibuatnya surat order sebagai bukti bahwa bank telah memberikan perintah kepada Notaris untuk menerbitkan akta-akta yang diperlukan ketika bank tidak bertemu langsung dengan Notaris. 
Notaris/PPAT meminta bank menerbitkan surat order agar Notaris/PPAT dan bank masingmasing mempunyai lampiran sebagai bukti pengikatan hak tanggungan dalam pemberian kredit, dan ketika oleh Notaris/PPAT surat order telah diterima maka Notaris/PPAT akan menerbitkan Covernote yang dijadikan bukti jaminan/pegangan sementara oleh bank dalam mencairkan kredit. Covernote yang diterbitkan oleh Notaris/PPAT tersebut merupakan surat yang menjadi dasar bagi bank untuk mencairkan kredit kepada debitur, tanpa surat order, Notaris/PPAT tidak dapat menerbitkan covernote dan APHT.

Dalam praktek, tidak semua bank menggunakan surat order dalam proses pengikatan agunan kredit. Bank-bank seperti PT. Bank Central Asia (Persero) Tbk.(BCA), PT. Bank Negara Indonesia (Persero) Tbk. (BNI), PT. Bank Rakyat Indonesia (Persero) Tbk. (BRI), PT. Bank Pembangunan Daerah Bali (BPD Bali) menggunakan surat order dalam pengikatan hak tanggungan. Tetapi, Bank Perkreditan Rakyat (BPR), bahkan beberapa kantor cabang pembantu beberapa bank besar tersebut di atas, tidak menggunakan surat order dan biasanya langsung datang atau hanya menelpon Notaris.

Surat order merupakan bagian yang tak terpisahkan dari perjanjian utang piutang dalam proses pemberian hak tanggungan, di mana sebelum dibuatnya perjanjian kredit haruslah didahului dengan pemberian surat order oleh bank kepada Notaris. Terdapat kekosongan norma di dalam pengaturan penggunaan surat order sebagaimana diatur dalam Pasal 10 ayat (1) UndangUndang Republik Indonesia nomor 4 tahun 1996 tentang Hak
Tanggungan atas Tanah Beserta Benda-Benda yang Berkaitan dengan Tanah (UUHT).

\subsection{Rumusan Masalah}

Berdasarkan latar belakang permasalahan, maka dapat dirumuskan pokok permasalahan yang akan dibahas dalam penulisan tesis ini adalah sebagai berikut:

1. Bagaimanakah pengaturan surat order dalam peraturan perundang-undangan yang mengatur pengikatan agunan kredit perbankan?

2. Bagaimanakah formulasi pengaturan surat order untuk menjamin kepastian dan validitas Covernote dan APHT?

\subsection{Tujuan Penelitian}

Tujuan penelitian senantiasa mengikuti apa yang telah menjadi rumusan masalah dan menjelaskan apa yang ingin diperoleh dalam proses penelitian. Karena itu, tujuan penelitian harus jelas dan tegas serta memiliki keterkaitan dengan rumusan masalah. ${ }^{2}$ Adapun tujuan dari penulisan tesis ini adalah:

\subsubsection{Tujuan Umum}

Penelitian ini dilakukan untuk mengetahui situasi nyata dalam dunia perbankan mengenai pengaturan penggunaan surat order dalam proses pengikatan agunan kredit, serta memberikan pemahaman yang lebih mendalam mengenai pentingnya penggunaan surat order yang dibuat oleh bank kepada Notaris/PPAT.

\subsubsection{Tujuan Khusus}

$$
\begin{aligned}
& \text { 1. Untuk mengetahui dan } \\
& \text { menganalisis praktek } \\
& \text { penggunaan surat order dalam } \\
& \text { proses pengikatan agunan } \\
& \text { kredit oleh Bank. }
\end{aligned}
$$

${ }^{2}$ I Made Pasek Diantha, 2015, Metodologi Penelitian Hukum Normatif Dalam Justifikasi Teori Hukum, Prenada Media Group, Jakarta, h. 114. 
2. Untuk mengetahui dan menganalisis pengaturan penggunaan surat order dalam proses pengikatan agunan kredit untuk menjamin validitas Covernote dan APHT.

\subsection{Landasan Teori}

Untuk mengkaji permasalahan dalam jurnal ini, akan digunakan beberapa teori hukum antara sebagai berikut:

\section{Stufenbau Theory}

Hans Kelsen yang

berpendapat bahwa norma-norma hukum itu berjenjang-jenjang dan berlapis-lapis dalam suatu hierarki tata susunan, dimana suatu norma yang lebih rendah berlaku, bersumber dan berdasar pada norma yang lebih tinggi pada puncak yaitu norma dasar (Grundnorm). ${ }^{3}$ Hans Kelsen mengemukakan bahwa sistem hukum pada hakekatnya adalah sebuah hirarki norma hukum dengan berbagai jenjang yang kesatuannya diwujudkan oleh kaitan yang tercipta dari fakta bahwa keabsahan suatu norma yang diciptakan sesuai dengan norma lain. ${ }^{4}$

2. Teori Kepastian Hukum

Kepastian hukum yang dimaksud dalam teori ini untuk setiap perbuatan hukum dan debitur dapat menjamin kepastian hukum bagi para pihak. mengandung dua pengertian yaitu pertama adanya aturan yang bersifat umum membuat individu mengetahui perbuatan apa yang boleh dan tidak boleh dilakukan; lagi, demikian seterusnya sampai dilakukan oleh pihak kreditur Teori kepastian hukum

dan yang kedua berupa keamanan hukum untuk dapat mengetahui apa saja yang boleh dibebankan atau dilakukan oleh Negara terhadap individu. ${ }^{5}$

3. Teori Tanggung Jawab dan Kewenangan

Suatu teori yang terkait dengan teori mengenai kewajiban hukum adalah teori tanggung jawab hukum (liability). Seseorang yang bertanggung jawab secara hukum atas perbuatan tertentu bahwa dia dapat dikenakan suatu sanksi dalam kasus perbuatannya bertentangan atau berlawanan dengan hukum. Sanksi dikenakan, karena dari perbuatannya sendiri yang membuat orang tersebut bertanggungjawab. Subyek terhadap responsibility dan subyek dari kewajiban hukum adalah sama. Dalam teori tradisional, ada dua jenis tanggung jawab yaitu pertanggungjawaban yang berdasarkan pada kesalahan (based on fault) dan pertanggungjawab mutlak (absolute liability) ${ }^{6}$.

Berdasarkan teori ini, apabila surat order tidak dikeluarkan oleh bank, maka harus ada pihak yang bertanggung jawab atas tidak dikeluarkannya surat order tersebut. Pihak yang mengeluarkan surat order harus berwenang secara hukum atau memiliki kewenangan yang diberikan oleh pemerintah, undang-undang, atau instansi-instansi terkait. Untuk menjawab hal tersebut wajib dilihat melalui teori kewenangan.

Fokus kajian teori kewenangan adalah berkaitan dengan sumber

${ }^{3}$ Jimly Assiddiqie \& M. Ali Safa'at, 2006, Teori Hans Kelsen Tentang Hukum, Konstitusi Press, Jakarta, h. 109.

${ }^{4}$ Raisul Muttaqien, 2011, Teori Hukum Murni, terjemahan Hans Kelsen, diterjemahkan dari buku asli Pure Theory of Law, Cet. IX, Nusa Media, Bandung, h. 244.
${ }^{5}$ Peter Mahmud Marzuki, 2008, Pengantar Ilmu Hukum, Kencana, Jakarta, h. 137.

${ }^{6}$ Jimly Asshiddiqie, Ali Safa'at, 2006, Teori Hans Kelsen tentang Hukum, Jakarta, Konstitusi Press, h. 61. 
kewenangan dari pemerintah dalam melakukan perbuatan hukum dalam hubungannya dengan hukum publik maupun dalam hubungannya dengan hukum privat. Menurut teori kewenangan, terdapat tiga macam/jenis kewenangan yang bersumber dari undang-undang yang meliputi delegasi, atribusi, dan mandat.

\section{METODE PENELITIAN}

\subsection{Jenis Penelitian}

Penyusunan tesis ini menggunakan penelitian hukum normatif ${ }^{7}$ dengan mengkaji permasalahan berlandaskan aturan-aturan dan berdasarkan teori-teori hukum.

\subsection{Jenis Pendekatan}

Penelitian ini menggunakan Pendekatan Perundang-undangan (Statute Approach) dan Pendekatan Historis (Historical Approach $)^{8}$.

\subsection{Sumber Bahan Hukum}

1. Bahan Hukum Primer:

1) Undang-Undang

Dasar Negara Republik Indonesia 1945

2) Kitab Undang-Undang Hukum Perdata (Burgerlijk Wetboek) yang diterjemahkan ke bahasa Indonesia oleh R. Subekti dan Tjitrosudibio

3) Undang-Undang Republik Indonesia Nomor 10 Tahun 1998 tentang Perbankan

4) Undang-Undang Republik Indonesia Nomor 4 Tahun 1996 tentang Hak Tanggungan Atas Tanah Beserta Benda-Benda Yang Berkaitan Dengan Tanah

5) Undang-Undang Republik Indonesia Nomor 2 tahun 2014 tentang Perubahan atas

${ }^{7}$ Ida Bagus Wyasa Putra, 2016, Teori Hukum Dengan Orientasi Kebijakan, Udayana University Press, Denpasar, h. 57.

${ }^{8}$ Ida Bagus Wyasa Putra, 2015, Filsafat Ilmu Filsafat Ilmи Hukum, Udayana University Press, h. 161
Undang-Undang nomor 30 tahun 2004 tentang Jabatan Notaris

6) Undang-Undang Republik Indonesia Nomor 3 Tahun 2004 tentang Perubahan Atas Undang-Undang Nomor 23 Tahun 1999 tentang Bank Indonesia

7) Undang-Undang Republik Indonesia Nomor 21 Tahun 2011 tentang Otoritas Jasa Keuangan

8) Peraturan Bank Indonesia Nomor 8/4/PBI/2006 Tentang Pelaksanaan Good Corporate Governance Bagi Bank Umum

2. Bahan Hukum Sekunder

Bahan hukum sekunder berupa semua publikasi tentang hukum yang bukan dokumen-dokumen resmi.

\subsection{Teknik Pengumpulan Bahan Hukum}

Mengenai teknik pengumpulan bahan hukum yang akan digunakan dalam penelitian ini sebagaimana yang dikemukakan oleh Mukti Fajar dan Yulianto Achmad yang menyebutkan bahwa teknik pengumpulan bahan hukum dalam penelitian hukum normatif dilakukan dengan studi pustaka terhadap bahan-bahan hukum, baik bahan hukum primer, bahan hukum sekunder, maupun bahan hukum tersier. ${ }^{9}$

\subsection{Teknik Analisis Bahan Hukum}

Seluruh bahan hukum yang telah terkumpul dalam penelitian selanjutnya dipilah diklasifikasikan, dibandingkan antara satu bahan hukum dengan bahan hukum yang lainnya, diinterpretasi lalu dianalisis dengan menggambarkan secara menyeluruh serta detail aspek-

${ }^{9}$ Mukti Fajar dan Yulianto Achnmad, 2010, Dualisme Penelitian Hukum. Normatif dan Empiris, Pustaka Pelajar, Yogyakarta, h. 160. 
aspek yang berkaitan dengan permasalahan untuk mendapatkan kebenaran. Langkah-langkah yang dilakukan dalam menganalisis permasalahan adalah dengan pengolahan terhadap bahan-bahan hukum yang telah dikumpulkan. Dalam menjawab isu hukum yang telah dirumuskan dalam rumusan masalah dilakukan dengan kegiatan penalaran ilmiah terhadap bahan-bahan hukum yang dianalisis, baik menggunakan penalaran induksi, deduksi, maupun abduksi.

\section{HASIL DAN PEMBAHASAN \\ 3.1. Praktek Penggunaan Surat Order Dalam Proses Pengikatan Agunan Kredit Oleh Bank}

Surat order termasuk dalam jenis surat resmi karena dikeluarkan oleh instansi yaitu bank. Untuk menjamin valid atau sahnya surat order, harus dipenuhi syarat umum dan khusus yang dimiliki surat resmi. Surat order merupakan surat yang dikeluarkan oleh bank untuk memohon bantuan jasa Notaris/PPAT dalam pemasangan hak tanggungan terhadap jaminan yang diberikan oleh debitur. Surat order sangat erat kaitannya dalam pembuatan APHT. Maka terdapat syarat khusus yang harus tertulis dalam surat order yaitu:

1. Identitas lengkap pihak debitur dan kreditur;

2. Hal-hal yang dimohonkan kepada Notaris/PPAT;

3. Jenis fasilitas kredit yang diberikan serta plafond kredit;

4. Data lengkap obyek jaminan yang diberikan debitur.

Kedudukan surat order dalam proses pemberian kredit sangat penting ketika akan melakukan pengikatan terhadap jaminan kredit. Penting dibuatnya surat order ketika bank dan Notaris/PPAT tidak bertemu secara langsung untuk menjamin validitas dari data-data yang akan dicantumkan dalam APHT. Surat order mempunyai kekuatan hukum yang dapat digunakan sebagai alat bukti tertulis, suatu bukti yang sah, "hitam di atas putih". Surat order dalam arsip lama dapat dipakai sebagai bahan penelitian untuk mengetahui bagaimana kegiatan atau keadaan pada masa yang lalu. Dalam hal ini, surat order berfungsi sebagai alat bukti historis. Surat-surat yang telah diarsipkan itu dipakai sebagai alat pengingat.

Menurut Dr. I Gusti Putu Anom Kerti, SH., M.Kn Notaris di Kabupaten Badung berpendapat bahwa, "Kedudukan surat order sangat penting dalam proses pemasangan hak tanggungan, yaitu untuk menjamin validitas dari data-data yang diberikan oleh bank untuk menghindari terjadinya malpraktek pembuatan APHT serta Notaris/PPAT mempunyai pegangan untuk mengeluarkan Covernote". Notaris/PPAT tidak akan mengeluarkan Covernote apabila tidak diberikan surat order apabila tidak bertemu langsung dengan bank. Lebih lanjut lagi berdasarkan hasil wawancara dengan beliau, walaupun banyak notaris yang tidak mengisyaratkan penggunaan surat order untuk mempercepat proses pemberian kredit, telah banyak notarisnotaris yang mengharuskan bank untuk menggunakan surat order dalam suatu proses pemberian kredit terutama apabila nilai pinjamannya besar atau tinggi. Beberapa notaris yang mengisyaratkan penggunaan surat order diantaranya I Gusti Putu Anom Kerti, I Gusti Ngurah Agung Putra Wibawa, Ida Ayu Dwipayatni, dan notaris-notaris lainnya. 


\subsection{Formulasi Pengaturan Penggunaan Surat Order Dalam Menjamin Validitas Covernote Dan Apht}

Sebagaimana dijelaskan pada pembahasan sebelumnya, dapat diketahui bahwa Belum terdapat suatu pengaturan yang mengatur secara khusus mengenai penggunaan surat order yang dikeluarkan oleh bank untuk Notaris/PPAT dalam proses pengikatan agunan kredit untuk menjamin validitas Covernote dan APHT ketika bank dan Notaris/PPAT tidak bertemu secara langsung. Tidak bertemunya secara langsung antara pihak bank dengan PPAT menimbulkan pertanyaan mengenai validitas atau kepastian hukum dari data-data yang diberikan pihak bank dalam rangka menjalankan proses pengikatan agunan pada pemberian kredit oleh bank kepada debitur.

Mengenai penggunaan surat order yang dibahas dalam tesis ini, perlu adanya aturan yang mengatur tentang penggunaan surat order serta diperlukan adanya aturan yang menjelaskan tentang bentuk dan syarat dari surat order itu sendiri. Bentuk dan syarat surat order perlu diatur agar terdapat keseragaman bentuk dan isi dari surat order yang dikeluarkan oleh masing-masing bank. Terkait tidak adanya pengaturan yang secara khusus mengatur mengenai penggunaan Surat Order dalam proses pengikatan agunan kredit, rekonstruksi hukum dilakukan yaitu pada Pasal 10 UUHT yang tampaknya relevan untuk ditambahkan beberapa ayat baru untuk mengakomodir keadaan dari penggunaan Surat Order (kekosongan norma) yang digunakan sebelum pembuatan APHT oleh PPAT.
Berikut adalah formulasi hukum dari pengaturan penggunaan Surat Order dalam pemberian kredit oleh bank yang dapat tertuang dalam Peraturan OJK:

$$
\text { Pasal } 1
$$

"Penyampaian data-data objek yang akan diberikan hak tanggungan diberikan oleh bank kepada PPAT dibuat tertulis dengan menggunakan Surat Order" Pasal 2

"Surat order merupakan surat yang dikeluarkan oleh Bank kepada Notaris/PPAT untuk menyampaikan data-data objek jaminan kredit dan memberi order atau perintah bank dalam proses pemasangan hak tanggungann terhadap jaminan yang diberikan oleh debitur"

\section{Pasal 3}

"Isi dari Surat Order adalah:

1. Menggunakan kop surat yang terdiri dari:

a. Nama instansi atau bank, ditulis dengan huruf capital atau huruf besar.

b. Alamat instansi atau bank, ditulis dengan variasi huruf besar dan kecil.

c. Logo instansi atau bank

d. Nomor surat, yakni urutan surat yang dikirimkan

e. Lampiran, berisi lembaran lain yang disertakan selain surat

f. Hal, berupa garis besar isi surat

g. Tanggal surat (penulisan di sebelah kanan sejajar dengan nomor surat)

h. Alamat yang dituju (jangan gunakan kata kepada)

i. Pembuka/salam pembuka (diakhiri tanda koma)

2. Isi surat

3. Penggunaan Bahasa Indonesia resmi;

4. Penutup surat yang terdiri dari:

a. Salam penutup

b. Jabatan 
c. Tanda tangan

d. Nama (biasanya disertai nomor induk pegawai atau NIP)

5. Tembusan surat, berupa penyertaan atau pemberitahuan kepada atasan tentang adanya suatu kegiatan;

6. Menyertakan cap atau stempel dari instansi atau bank resmi."

\section{Pasal 4 \\ "Di dalam surat order wajib dicantumkan: \\ 1. Identitas lengkap pihak debitur dan kreditur; \\ 2. Hal-hal yang dimohonkan atau perintah bank kepada Notaris/ PPAT;}

3. Jenis fasilitas kredit yang diberikan serta plafond kredit;

4. Data lengkap obyek jaminan yang diberikan debitur."

Pemberian empat pasal baru yang akan tertuang dalam Peraturan BI atau Peraturan OJK merupakan suatu usaha dalam rangka memberikan kepastian hukum terhadap permasalahan yang telah diapaparkan pada pembahasan sebelumnya, yaitu tidak adanya pengaturan (kekosongan norma) yang mengatur mengenai penggunaan surat order dalam proses pengikatan agunan kredit demi menjamin validitas data-data yang diberikan oleh bank kepada Notaris/PPAT ketika tidak bertemu langsung.

\section{PENUTUP}

4.1. Kesimpulan

Berdasarkan pembahasan yang telah dipaparkan dalam bab-bab sebelumnya, maka dapat ditarik kesimpulan sebagai berikut:

1. Pengaturan penggunaan Surat Order dalam Peraturan Perundang-undangan yang mengatur pengikatan agunan kredit perbankan masih tidak memadai untuk digunakan.
Terdapat kekosongan norma pada Pasal 10 UUHT mengenai pengaturan terhadap persyaratan dan penggunaan Surat Order dalam menjamin validitas datadata sebelum dikeluarkannya covernote dan APHT oleh notaris/PPAT.

2. Formulasi pengaturan Surat Order untuk menjamin validitas dan memberikan kepastian hukum dari Covernote dan APHT dilakukan dengan membuatkan aturan yang tertuang pada Peraturan OJK sebagaimana telah sesuai dengan kewenangannya berdasarkan undang-undang untuk memberikan pengaturan terhadap bank. Pembuatan aturan baru oleh OJK adalah untuk mengisi kekosongan norma pada pengaturan persyaratan dan penggunaan Surat Order dalam proses pengikatan agunan kredit; dan untuk menjamin valid atau tidak validnya data-data yang dituangkan di dalam covernote dan APHT. Pembuatan aturan dilakukan dengan menambahkan pengaturan mengenai persyaratan Surat Order, bentuk resmi Surat Order, dan penggunaan Surat Order dalam proses pengikatan agunan kredit.

\subsection{Saran}

Beberapa saran yang dapat diajukan adalah sebagai berikut:

1. Pemerintah dan Pembuat Undang-Undang hendaknya melakukan perbaikan atau amandemen dengan membuatkan aturan-aturan yang secara khusus dan menyeluruh mengenai penggunaan Surat Order, baik itu persyaratan maupun penggunaannya. Hal tersebut akan menjadi sangat penting karena dengan digunakannya Surat Order oleh pihak bank dalam proses 
pengikatan agunan, selain untuk menjamin validitas data-data di dalam Covernote dan APHT, Surat Order juga akan menciptakan lingkungan pekerjaan yang tertib administrasi.

2. Perbankan dan Notaris/PPAT di Indonesia hendaknya lebih memahami dan memperhatikan fungsi dan kelebihan-kelebihan dari digunakannya Surat Order dalam proses pengikatan agunan kredit. Selain dapat menguntungkan kedua pihak (Bank dan Notaris), Surat Ordeer juga sebagai media pelindung bagi pihak bank dan juga pihak Notaris apabila terjadi permasalahan di kemudian hari.

\section{DAFTAR PUSTAKA}

Assiddiqie, Jimly \& M. Ali Safa'at, 2006, Teori Hans Kelsen Tentang Hukum, Konstitusi Press, Jakarta.

Fajar, Mukti dan Yulianto Achnmad, 2010, Dualisme Penelitian Hukum. Normatif dan Empiris, Pustaka Pelajar, Yogyakarta.

Hermansyah, 2008, Hukum Perbankan Nasional Indonesia, Kencana Prenada Media, Jakarta.

Ibrahim, Johnny, 2012, Teori dan Metodologi Penelitian Hukum Normatif, Cet. VI, Bayumedia Publishing, Malang.

Marzuki, Peter Mahmud, 2008, Pengantar Ilmu Hukum, Kencana, Jakarta.

Muttaqien, Raisul, 2011, Teori Hukum Murni, terjemahan Hans Kelsen, diterjemahkan dari buku asli Pure Theory of Law, Cet. IX, Nusa Media, Bandung.

Pasek Diantha, I Made, 2015, Metodologi Penelitian Hukum Normatif Dalam Justifikasi Teori Hukum, Prenada Media Group, Jakarta.

Wyasa Putra, Ida Bagus, 2015, Filsafat Ilmu Filsafat Ilmu Hukum, Udayana University Press, Denpasar.

Wyasa Putra, Ida Bagus, 2016, Teori Hukum Dengan Orientasi Kebijakan, Udayana University Press, Denpasar.

\section{PERATURAN PERUNDANG-UNDANGAN}

Undang-Undang Dasar Negara Republik Indonesia tahun 1945

Kitab Undang-Undang Hukum Perdata (Burgerlijk Wetboek) yang diterjemahkan ke bahasa Indonesia oleh R. Subekti dan R.Tjitrosudibio

Undang-Undang Republik Indonesia Nomor 4 Tahun 1996 tentang Hak Tanggungan Atas Tanah Beserta Benda-Benda Yang Berkaitan Dengan Tanah

Undang-Undang Republik Indonesia Nomor 10 Tahun 1998 tentang Perbankan

Undang-Undang Republik Indonesia Nomor 2 tahun 2014 tentang Perubahan atas Undang-Undang nomor 30 tahun 2004 tentang Jabatan Notaris

Peraturan Bank Indonesia Nomor 8/4/PBI/2006 Tentang Pelaksanaan Good Corporate Governance Bagi Bank Umum 